geldt hetzelfde als ten aanzien van de zeggenschap over de uitdelingen.

Maar hoc wanneer groot-aandeelhouder $A$ van zijn macht misluruik heeft gemakt en zich zclf, ten nadele van de andere aandeelhouders, een beloning heeft bezorgd die groter is dan zijn arbeid ward is? Als ik het wel heb, kumnen de andere aandeelhouders aan deze dieverij - althans in beginsel door den rechter vool de tockomst een eind doen maken; elk besluit van de algemene vergadering moet naar redelijkheid en billijkheid genomen worden (v. d. Heyden no. 223, p. 179). Maar daarvan afgezien: wil men de verkoopwarde van $A$ 's aandelen bepalen, dan kan men or bezwarlijk van uitgaan, dat er een koper met dezelfde dievenneiging zal opdagen; men zal dus een normaal salaris en een normaal dividend in aanmerking nemen. Maar dan trekt A nóg een extra-bate, zịnde het deel van zijn surplus-salaris dat ten laste van de andere aandeelhouders kwam; dit blijft buiten aanmerking als men de verkoopwarde bepaalt. Meent men echter te moeten waarderen wat deze eigenaar aan toekomstige ophrengsten lian verwachten - de Hoge Ralad stun rt in die richting - on meent men dat de bedoelde extra-bate als een opbrengst van de aandelen moet worden aangemerlit (van de juistheid van deze mening ben ik niet aanstonds overtuigd, al willen we allemaal ook nog zo graag dat de gannef moet betalen), dân zou men voor dit uitzonderingsgeval een wetstoepassing krijgen, waarbij van ,verkoopwaarde" wordt afgeweken en waarbij de persoon van den aandeelhouder van invloed op de waardering is.

Maar dan rormt de\%e zeer speciale afwijking toch nog een geheel onvoldoend fundament - ook al neemt men de steen die de Hoge Rad heeft bijgedlagen in aanmerking - voor het weidse gebouw, dat Adriani, en ook Meyburg, willen optrekken op het thema, dat de verhouding van den aandeelhouder tot de N.V. voor de methode van waardebepaling van incourante aundelen van groot belang is.

Adriani (Vermogensbelasting p. 241) stelt niet minder dan dat ,de functie van den andeclhouder ten opzichte van de N.V. van geheel uiteenlopende betekenis kan zijn" en dat ,bij de schatting (van de wararde van cen incourant aandecl) moet urorden uitgegaan v'an (cursivering van mij, de L.) die functie".

Meyburg (M.A.B. Juni 1938 p. 89 e.v.) treedt in zijn voetspoor bij zịjn schets van de verschillende schema's voor de waardering van incourante aandelen," die o.a. afhankelijk zijn van..... de functie, welke het aandeel in het vermogen van den bezitter heeft".

'Terwijl mijn opkomen in $\$ 2$ tegen de vermeende tegenstelling tussen geldswarde cn verkoopwaarde praktische betekenis heeft met betrekking tot die incourante aandelen, die enigszins geregeld verhandeld worden, heeft hetgeen ik hier wil stellen slechts theoretische betekenis met betrekking tot die aandelen, warvoor men op een berekening is aangewezen. Want over de conclusies, die de genoemde schrijvers trekken, zal hicr niet gesproken worken. Betwist wordt echter de wijze van voorstclling als zouden deze conclusies iets te maken hebben - afgezien van bovenbedoeld speciaal geval — met ,de functie van den aandeelhouder ten opzichte van de N.V." of met ,de functie, welke het aandeel in het vermogen van den bezitter heeft"

Men onderzocke cens - de toegestane plaatsiruimte laat niet toc daarop hier in te gaan - de verschillende govallen die door Adriani en Meuburg zijn genoemd; men zal steeds bevinden, dat het antwoord watrtoe zij komen uitsluitend berust op de aard van de N.Y. en niet op de persoon van den aandeclhouder, of op de samenstelling van zijn overig vermogen of het verband tussen de aandelen cn de overige vermogensbestanddelen.

Daarnaast komt het nuttig voor wanneer meer in het oog worde gehouden — wat naar mijn moning ook in de praktijk foor schatters niet altijd voldoende geseliedt - dat de verschillende ,walden", warover de genoemde en andere schrijvers uitweiden, niet meer zijn dan verschillende berekeningswijzen, die bij volledige toepassing, d.w.z. met aanbrenging van die correctics, die in clk concrect geval bij cen bepaalde berekeningswijze behoren ${ }^{4}$ ), alle tot dezelfde uitkomst mocten leiden. Want er is maar één beginsel, maar cén waardehepaling: de schatting van de contante walde van de verwachte tockomstige opbrengsten.

W. J. DE LANGFN

\section{DE BEPALING VAN DE WAARDE VAN AANDEELEN IN BESLOTEN VENNOOTSCHAPPEN}

De ,besloten" vennootschap onderscheidt zich in velcrlei opzicht van de „open" vennootschap.

Jet aantal andechouders is bij de besloten vennootselap, in tegenstelling met de open vemnootschap, beperkt. Vaak staan de andeclhouders tot clkaar in eene bepalde familieverhouding, waarom de besloten vennootschap ook wel familie-venneotschap wordt genoemd. De aanderlen staan in den regel op naam. Vervrcemding en overdracht van aandeelen zijn dan statutair geregeld en aan beperkende bepalingen onderworpen. Indien men aandeclen wil verkoopen, mocten zij eerst aan de aandeclhouders worden aangeboden; cerst daarna kan men tot verkoop aan derden overgaan, terwijl dit laatste, wat betreft den persoon van den nieuwen aandeelhouder, dan nog de goedkeuring van de directie moet hoblen. Bij sommige vennootschappen wordt jaarlijks in de algemeene vergadering de koers vastgesteld, waartegen overdracht aan aandeelhouders moet plaats hebben.

Overdracht van aandeelen heeft dus zclden plaats. Van eene beursnoteering is uit den aard der zaak geen sprake. Kan men bij de genoteerde aandeelen spreken van eene objecticve waarde, die geregeld wordt door vraag on aanbod, de waarde van de aandeclen in de besloten vennootschap is subjectief, doordat zij voor onbepaalden tijd in het bezit blijven van den aandeelhouder. Bij de waardebepaling van de aandeelen moet dus uitgegaan worden van de warde, die de aandeclen voor den aandeelhouder persoonlijk hebben. Deze warde kan voor de verschillende aandeelhouders der besloten vennootschap uiteenloopend zijn. Dit treedt duidelijk of den voorgrond, wanneer de directeuren der vennootschap door hun aandeelenbezit eene overwegende machtspositie innemen en daardoor in de gelegenheid zijn zichzelven een abnormaal hoog salaris en een, buiten verhouding van de winst, zecl hoog tantième toe to kennen. Voorts is er onderseheid te maken tusschen grootaandeelhouders en aandeelhouders, die door hun gering aandeelenbezit geen macht kunnen uitocfenen. Het groote verschil in machtspositic is vooral van beteekenis bij die vennootschappen, wall de winstverdeeling in de statuten niet nauwkeurig is geregcld, maar vecl is overgelaten aan de beslissing van de algemeene vergadering, hetgeen veelal leidt tot uitkeering van slechts cen gedeelte van de voor uitdeeling beschikbare winst. 'Ten slotte komt het nog voor, dat aan bepaalde aandeclen bijzondere rechten zijn tocgekend. De houders van deze aandeclen hebben dan $0 . m$. het recht eene bindende voordracht op te maken voor de benoeming van directeuren en com-

$\left.{ }^{4}\right)$ Heel wat gemalkkelijker maar daarom niet beter - want zij verdoezelt te veel - is de usance on de verschillende ongecorrigeerde berekeningswijzen elkander te laten corrigeren. 
missarissen. Ook hicr is dus wecr sprake van cene bijzondere machtspositic.

Bij de bepaling van de waarde van aandeelen in besloten vemnootschappen moet onderscheid worden gemaakt tusschen de vennootschappen, dic beleggingsmaatschappij zijn en de vennootschappen, die een bedrijf uitoefenen.

\section{Beleggingsmaatschappij.}

Zijn in de vennootschap allecn beleggingswarden (huizen, effecten, geldleeningen, e.a.) aanwezig, dan biedt de vaststelling ran de waarde der aandeelen in het algemeen geen moeilijkheden; zij wordt dan bepaald door de waarde van de bezittingen des venmootschap onder aftrek van de schulden.

Bepaling van de urarde van aandeelen in besloten vennootschappen, die een bedriff uitoefenen.

We zullen ons in de cerste plaats moeten afvragen, wat de grondslagen voor de bepaling van de waarde zijn. De waarde van de aandeelen wordt beheerscht door twee factoren : het in de onderneming aunwezige vermogen en het te verwachten rendement. De waarde der aandeelen is n.l. afhankelijk van het vermogen dat in de onderneming aanwezig is en de vergoeding, die over dit vermogen zal worden verkregen. Door beide gegevens, vermogen en rendement, met elkaar in verband to brengen, zal men tot vaststelling van de wadrde van de aandeelen moeten komen.

Ons doel zal dus moeten zijn het verzamelen van de noodige gegevens, die zullen leiden tot het vaststellen van het aanwezige vermogen on het te verwachten rendement.

Wij zullen voor ene systematische behandeling uitgaan van het geval, dat:

1. de andeelen onder de verschillende aandechouders min of meer gelijkmatig zijn verdeeld, althans niet een of enkele aandeelhouders tegenover de overige aandeclhouders vrijwel alle macht in handen hebben.

2. de statuten eene normale winstverdeeling angeven.

Bij het verzamelen van de gegevens voor het door ons gestelde doel nemen de jairrekeningen van de afgeloopon jaren een eerste plats in. Z Zij verschaffen de gegevens van het in de onderneming vastgelegde velmogen, van de winsten en van de uitgelsecrde dividenden.

De grootte van het in de onderneming aanwezige vermogen wordt vastgesteld aan de hand van de balans van het laatste boekjaar. Dit rermogen wordt bepaald door het gestorte kapitaal te vermeelderen met do open en de stille reserves.

De vaststelling ran de aanwezige stille rescrves brengt bij handelsondernemingen nict die moeilijklieden mede, die zich bij industriecle en cultuurondernemingen voordocn. De beide laatste groepen toch hebben zcor groote bedragon vastgelegd in duurzame product:onidaclen. De boekwaarce dezer productiemiddelen zal in don regel nict c.e huidige bodrijjswaarde vertegenwoordigen: do afschrijuing nn kumen in het verlecien abnormaal zijn geweest, bovendion lian de corspronkelijke aansehaffingswaarde bclangrijls afwijlsen ran ec tegenwoordigo vervangingswaarce. Eche schatting zal dus mocten plaats hebben van de waarde ran den grond en van de huidige losten bij nicuwbouw of aanschaffing, welke kosteu verminderd moeten worden met de noodzakelijke afschrijving wegens het ge- bruik in het verleden. Voor de eultuuronderneming zal men o.m. de huidige waarde van den in cultuur gebrachten grond moeten vaststellen. Eene aanwijzing voor leze waarde zal somtijjds kunnen zijn de prïjs per eenheid van gelijksoortige ondernemingen bij verkoop in het verleden. De vaststelling van de warde van de duurzame productiemiddelen biedt vaak groote moeilijkheden, cene taxatie door deskundigen is dan noodzakelijk.

Behalve de duurzame productiemiddelen komen ook de andere balansposten in a ammerking voor eene beoordecling. Do halanswaardeering van de overige activa on de verplichtingen, voorkomencle aan de ereditzijde van de balans, zullen achtercenvolgens moeten worden nagegaan. Voor zoover de activa te laag zijn gewardeerd of de verplichtingen te hoog zijn opgevoerd vormen zij stille reserves.

Met betrekking tot het gevormde pensioenfonds zullen de verplichtingen in zake de pensioenregeling met het personeel aan eene beschouwing mocten worden onderworpen. IIceft men tegrenover het jersoneel ten aanzien van ecne pensioenregeling verplichtingen aangegaan, dan zal het pensioenfonds zoo groot moeten zijn, dat aan deze verplichtingen zal kunnen worden voldaan. Bestaan er geen verplichtingen, maar wordt desondanks aan het personeel toch pensioen toegekend, dan zal de grootte van het gevormde pensioenfonds beoordeeld moeten worden aan de hand van de moveele verplichting, die men op zich heeft genomen.

Het spreekt vanzelf, dat men bij de vaststelling van het in de onderneming aanwezige vermogen niet alleen rekening moet houden met de stille reserves ten gevolge van te laag gewaardeerdo activa en te hoog opgevoerde verplichtingen, maar evenzecr met te hooge balanswardeering van activa en te laag opvoeren van verplichtingen in de balans, welke beiden tot een vermindering van het vermogen leiden.

Het te verwachten dividend wordt vastgesteld met behulp van de gedetailleerde winstrekeningen en bedrijfsstatistieken. Deze geven een overzicht van de winsten der opecnvolgende jaren en van de wijzigingen, die hebhen plaats gehad en de bedrijfsuitkomsten hebben beinvloed: het prịjzenverloop kan zich aanmerkelijk hebben gewijzigd; de afzetgebieden kunnen zijn ingekrompen of uitgebreid; de loonstandaard kan zijn veranderd; kostcnbesparing kan hebben plaatsgevonden. Met allo wijzigingen moet rekening worden gchouden. Van belang is immers niet wat de resultaten van het bedrijf in het verleden zijn gewcest, maar hoc zij in de toekomst zullen zijn.

Ilecft men $n_{a}$ bestudeering van alle gegevens inzicht gekregen in de tockomstige winstmogelijkheden van het bedrijf, dan zal men op grond van de statutaire bepalingen inzake de winstverdeeling kunnen vaststellen op welk dividend in de tockomst vermoedelijk zal kunnen worden gerekend. Ons uitgangspunt is geweest, dat de statutaire winstverdeeling als cenc normale was te beschouwen on de reservevorming dus niet verder gaat dan in verband met de risico's van het bedrijf moodzakclijk is.

Met behulp van het vastgestelde vermogen en het te verwachton dividend kan nu bepaald worden welke vergoeding over het in de onderneming aanwezige vermogen verkregen zal worden.

Hierbịj zijn dan een drietal gevallen te onderscheiden:

1e. het rendement kan in rerband met de risico's van het bcdrijf geacht worden eene normale vergoeding te zijn;

2e. het rendement is looger dan in geval 1 ;

3c. het rendement is lager dan in geval 1. 
Beschouwen we voor de waardeering der aandeclen achtereenvolgens de 3 gevallen.

\section{Geval 1.}

De vlaag doet zich voor: wat is eene normale vergoeding, in verband met de risico's van het bedrijf? Wat als normale vergoeding geldt, zal voor ieder bedrijf afzonderlijk moeten worden vastgesteld, daar zij afhankelijk is van de risico's, die aan het bedrijf verbonden zijn; overigens is zij afhankelijk van de rente op de kapitaalmarkt. Voor economisch- sterke en kapitalal-kl'achtige bedrijven zal men als normale vergocding kunnen rekenen cene rente, welke een paar procent ligt boven de rente van obligaties Nederlandsche Staatsleening.

De bepaling van de warde van de aandeelen is in geval 1 eenvoudig, zooals uit het volgende voorbeck zal blijken:

Stel het gestorte kapitaal $f$ 1.000.000.-, open + geheime reserves $f 500.000$.- ; het in de tockomst te verwachten dividend $9 \%$; de rente van obligaties Ned. Staatsl. \& \%. Kan in verband met de sterke positie, die het bedrijf inneemt, de normale vergoeding voor het in de onderneming aanwezige vermogen op $6 \%$ worden gesteld, dan wordt bij een dividend van $9 \%$ ecne vergoeding van $6 \%$ over het in de onderneming vastgelegde vermogen verkregen. De waarde van alle aandeelen is in het hier gckozen voorbeeld dus $f$ 1.500.000. - en de koers der aandeelen $150 \%$.

Bestaat het kapitaal der vennootschap uit gewoon en preferent kapitaal, dan zal het te verwachten dividend van beide soorten aandeelen volgens de statutaire winstverdecling moeten worden bepaald. Met het feit, dat preferente aandeelen bij winstverdeeling en in den regel ook bij liquidatic den voorrang genieten, moet bij de waardebepaling van deze aandeelen rekening worden gehouden. Bij liquidatie hebben de houders in den regel geen recht op aanwezige reserves. Het genoemde recht van voorrang zal de warde der preferente aandcelen gunstig beinvloeden. Het feit, dat de preferente aandeelhouders bij eventueele liquidatie geene rechten kumen doen gelden op de reserves, lcidt er toe, dat bij de wardebepaling van de preferente aandeclen alleen met het gestorte kapitaal en het dividend op deze aandeelen rekening is te houden.

\section{Geval 2.}

Zooals uit het bovenstaande is gebleken, is de bepaling van de warde van andeelen eenroudig, indien over het vermogen in de onderneming eene normale vergoeding mag worden verwacht. Hoe moet echter worden gehandeld, indien het toekomstig rendement boven het normale zal liggen? Welke waarde moet dan aan de extra-vergoeding worden toegekend? De extra-vergoeding wijst $\mathrm{er}$ op, dat in de onderneming een goodwill aanwezig is. I) waarde van dezen goodwill kan worden bepald door de extra-vergoeding te kapitaliseeren; daartoe kan men haar met ecn bepaald getal vermenigvuldigen. De grootte van dit getal is afhankelijk van de positie, die het bedrijf in het economische leven inneemt. Is deze positie zeer sterk te noemen, dan zal men het bedrag der extra-vergoeding b.v. 8 maal kunnen nemen. Indien niet mag worden aangenomen, dat over een lange recks van jaren op het hooge rendement kan worden gerekend, dan zal aan den goodwill eene lagere waarde moeten worden tocgekend.

Is in het hierboven gegeren roorbeeld het te verwachten dividend $14 \%$ en kan dit dividend in verband met de sterke positie van het bedrijf gedurende een lange recks van jaren worden verwacht, dan is de koer's der gewone aandeelen als volgt te berekenen:

Gestort aandeelenkapitaal + open en geheime rescrves $f$ 1.500.000.- .

De normale vergoeding over het vermogen in de onderne$\operatorname{ming}=6 \%$. Iliervoor is noodig een dividend van $9 \%$ over het gestorte aandeelenkapitaal van $f$ 1.000.000.- . Het dividend bedraagt $14 \%$, d.i. 5\% meer. De goodwill bedragt $8 \times 5 \%=40 \%=f+00.000 .-$. De totale warlde van alle aandeclen is derhalve te stellen op $f$ 1.900.000. - en de koers op $190 \%$.

\section{Geval 3.}

Behandelen we nu het geval, dat de toekomst-verwachtingen van het bedrijf zoodanig zijn, dat $4 \frac{1}{2} \%$ dividend zal worden uitgekeerd. In het hicrboven gekozen voorbeeld zal dan over gestort aandeelenkapitaal - open en geheime reserves, in totaal $f$ 1.500.000.-, slechts eene vergoeding van $3 \%$ worden verkregen. De toekomstige bedrijfsresultaten zullen dus zoodanig zijn, dat geen normale vergoeding van $6 \%$ zal worden verkregen. Op basis van het te verwachten dividend zou de waarde der aandeclen te stellen zijn op $3 / 6 \times 150 \%=75 \%$. Rekening moet dan echter nog worden gehouden met het feit, dat in de onderneming een vermogen aanwezig is van $f$ 1.500.000.-, d.i. $f 750.000$ - boven de warde van $f 750.000$. op basis van het dividend. Bij de vaststelling van de waarde der aandeclen mag echter niet wit het oog worden verloren, dat, hetgeen in de onderneming aan vermogen meer alanwezig is dan de $75 \%$ rendementswaarde der aundeelen, slechts in de verre toekomst tot uitkeering kan komen, zoodat van eene aanzienlijke verhooging van de rendementswarde geen sprake kan zijn. In hoeverre de koers boven de $75 \%$ zal kumnen worden vastgesteld is aflankeljjk van de in de onderneming aanwezige waarden. Bestaat het grootste gedeclte van het vermogen der onderneming uit dururame productiemiddelen, dan zal de warde der aandeclen slechts weinig boven de $75 \%$ liggen. Zịjn daarentegen belangrijke realiscerbare waarden en liquide middelen aanwezig, dan kan de verheoging van meer betcekcnis zijn.

Veel mecijijkcr wordt de waardcbepaling ran aandeclen, wamnecl gecn der dric hicrboren genoemde gevallen zich voordoet, maar het bedrijf slcelit gaat, de laatste jaren verliezen hebben gegeven en ook in de tockomst nog verliczen te wachten zijn. Is de toestand van het bedrijf van dien aard, dat binnon afzicnbaren tijd tot liquidatic zal mocten worden overgegaan, dan zal de koers der aandeelen op de liquidatiewaarde kunnen worden gesteld.

Voor bepaling van de liquidatiewaarde is van beteckenis welke waarde aan de duurzame productiemiddelen moct worden toegekend. Kumnen de gebouwen, machines, enz. door een ander bedrijf worden overgenomen, dan moet de vermoedelijke verkoopwaarde worden bepaald. Is dit niet het geval, dan zal de warde ran de duurzame productieniddelen op de waarde van den grond plus de afluraakwaarde van gebouwen, machines, enz. gesteld kumnen worden. Ook op goederen en vorderingen zullen in den regel bij liquidatie extra verliezen geleden wor. den. Ten slotte is bij de vaststelling van de liquidatiewarde der a andeelen nog rekening te houden met liquidatickosten.

Is de positie van de onderneming nog zoodanig, dat niet tot 
liquidatie behoeft te worden overgegaan en eene gunstige conjuncturu kan worden afgewacht, dan kan het voornemen bestaan, dat men met het oog op de geleden verliezen tot kapitaalsreorganisatic zal overgaan. De waarde van de aandeclen zal dan afhankelijk zijn van de grootte van het kapitaal na reorganisatic, wanneer alle verliezen zijn afgeschreven en van het rendement, dat bij een gunstiger conjunctum zal worden verkregen.

Zal nict tot kapitaalsrcorganisatic worden overgegaan, dan zal in de toekomst, wanneer er weer winst wordt gemaakt deze moeten worden aangewend tot dekking van het verlies en aanvulling van de reserve. Eerst dan zal er van dividenduitkeering weer sprake kumnen zijn.

In alle gevallen, wallin de bedrijfsresultaten in de afgeloopen jajen slecht zijn geweest en ook voor de naaste toekomst nog geene winstmogelyjkheden bestaan, zal de wardebepaling der aandeelen geheel op schatting moeten berusten. Wanneer betere tijdcn aanbreken, zullen er mecr positieve gegevens aanwezig zijn om tot cene bepaling van de warde van de aandeelen to komen.

Ten slotte nog eene opmertking over de wijze, waarop lict bedrijf wordt gefinancierd. Bij de waardebepaling van aandeclen zal onderseheid gemaakt moeten worden tussehen vennootschappen, dic geheel of nagenoeg geheel met eigen middelen van de aandechouders worden gefinancierd en vennootschappen, die een groot gedeelte van haar bedrijfskapitaal bij derden hebben opgenomen. Wordt het bedrijf met cen groot bankcrediet gefinancierd, dan zal in tijden van economische depressie de rentelast van dit crediet zwaar op de exploitatie van het bedrịf drukken; bovendien bestaat dan de mogelijkheid, dat het voortbestaan van de vennootschap wordt bedreigd, doordat het eredict sterk wordt ingekrompen of geheel wordt opgezegd. Zijn de geldmiddelen van het bedrijf voor een groot gedeclte verkiegen door het plaatsen van obligaties bij derden (dus buiten den kring van andeelhouders), die binnen afzienbaren tijd ter aflossing kummen worden aangeboden, dan zullen ook hier de verschuldigle rente en de verplichting tot aflossing in ongunstige tijden het bedrijf in moeilijkheden kunnen brengen.

In het algemeen zullen vennootsehappen, die voor de financiering van haar bedrijf voor een belangrijk gedeelte kapitaal bij derden hebben opgenomen, eerder in financieele moeilijkheden kunnen geraken. Dil feit zal bij de wardebepaling van de aandeclen in deze vernnotschappen in aannerking moeten worden genomen.

Het zal een nadecligen invloed uitoefenen op de warde van de aandeclen.

\section{De statuten geven geen normale winstverdeeling.}

In de statuten van de besloten vennootschap wordt ten aanzien van de winstverdecling meermalen de bepaling opgenomen, dat, nadat aan de aandeclhouder's een zeker dividend (bijv. $6 \%$ ) en aan directie en commissarissen tantième zal zijn uitgekeerd, de overige winst ter beschikking van de algemeene vergadering zal worden gesteld. Dit laatste heeft dan in den regel tot gevolg, dat de overige winst wordt gebruikt voor extra-afschrịving en reserveering.

Het uitgekeerde dividend is hier geen maatstaf voor het rendement van het in de onderneming geinvesteerde kapital. Wordt de ingehouden winst liquide belegd, dan kan zij ten allen tijde worden nitgekeerd. Vastgesteld zal in dit geval moeten worden, hoe groot het toekomstig dividend zal zijn bij normale afschrijving en reservevorming. Dit dividend zal bij de bepaling van de waarde der aandeclen in aanmerking moeten worden genomen.

In dit verband nog eene opmerking met betrekking tot het in de onderneming aanwezige vermogen. Komen in de toekomst de ingehouden winsten tot uitkecring, dan zal over de uitdeelingen dividend- en tantième-belasting moeten worden betaald. Bij de vaststelling van genoemd vermogen zal hiermede rekening zijn te houden.

Het uitkeeren van een klein gedeelte van de gemaakte winst heeft tot gevolg, dat, indien de niet uitgekecrde winst niet wordt aangewend in let bedrijf, in den loop der jaren zeer groote bedragen aan liquide middelen worden gevormd, die voor het bedrijf overbodig zijn. Wanneer dit geval zich voordoet, zal men bij de wardebepaling van de aandeelen het vermogen in de ondcrueming moeten splitsen in twee gedeelten: in cen vermogen, dat op het eigenlijke bedrijf en ecn vermogen, dat op belegging van voor het bedrijf overtollige geldmiddelen, betrekking heeft. Ook de winst zal gesplitst moeten worden in: een eigenlijke bedrijfswinst en inkomsten uit beleggingen van overtollige geldmiddelen. Zoodoende kan men komen tot cene beoordeeling van den toestand van het eigenlijke bedrijf.

De warde ran de aundeelen wordt dan bepaald door de waarde van le. het eigenlijke bedrijf en 2e. de belegging van de overtollige geldmiddelen.

De bepaling van de waarde van het bedrijf geschiedt op de wijze, zooals deze hierboven is aangegeven. Is deze waarde vastgesteld, dan moet zij vermeerderd worden met de waarde van de beleggingen der overtollige geldmiddelen. De som van beide waarden zal den koers der aandeelen bepalen.

$\mathrm{Bij}$ de beoordeeling van de belegringen, die voor het bedrijf overbodig zijn, zal men natuurlijk op voorzichtige wijze te werk mocten gaan. Bestaat er mogelijkheid van uitbreiding van het bedrijf, dan zal hiermede rekening moeten worden gehouden, zoo ook met eventueele aflossingen van opeischbare schulden (obligaties, deposito's e.a.).

Het aandeelenbezit is voor de verschillende aandechouders zeer viteenloopende.

$\mathrm{Bij}$ bovenstaande beschouwingen werd uitgegaan van cene min of meer gelijke verdecling van de aandeclen. In de praktijk is dit echter niet altijd het geval. Naast eene groep van grootaandeelhouders, dic de macht uitoefenen in de vennootschap, staat vaak een groep van aandeclhouders, die slechts enkele aandeclen bezitten en op de besluiten van de algemeene vergadering geen invloed kumnen uitoefenen. De aandeelhouders van deze minderheidsgroep zijn onderworpen aan de dividendpolitiek van de groot-aandeelhouders. Wordt volgens besluit van de algemeene vergadering slechts een gedeelte van de voor uitkeering beschikbare winst uitgedeeld, dan zal bij de waardebepaling van de aandeclen van de groot-aandeelhouders rekening moeten worden gehouden met de niet tot uitkeering gebrachte winst op de wijze, zooals hierboven werd aangegeven. Voor de aandechouders, die slechts cnkele aandeelen bezitten, zal bij de bepaling van de warde van humne aandeelen het uitgekeerde dividend in aanmerking komen. In tegenstelling met de groep groot-aandeelhouders hebben zij niet de macht de voor uitkeering beschikbare winst tot uitdeeling te brengen.

Nemen de bestuurders van de vennootschap door hun groot aandeelenbezit eene overwegende machtspositie in, dan komt het meermalen voor, dat zij hiervan gebruik maken door zichzelven een abnormaal hoog salaris en tantième toe te kennen. Voor zoover het salaris en het tantième meer dan eene normale belooning voor de bestuursfunctie zijn, zal aangenomen 
moeten worden, dat dit meerdere opbrengst is van hun grootaandeelenbezit. Alleen door dit groot-aandeelenbezit waren zij in de gelegenheid besluiten te nemen tot abnormaal hooge directie-salarissen en tantièmes. Bij de bepaling van de waarde der aandeelen van deze bestuurders zal dus het rendement nog moeten worden verhoogd met het genoten extra-salaris en extratantième.

\section{Bijzondere rechten aan het bezit van bepaalde aandeelen ver-} bonden.

Somtijds wordt bij oprichting van besloten vennootschappen naast de gewone aandeelen een klein aantal aandeelen uitgegeven, waaraan bijzondere rechten zịn verbonden. De uitgifte van laatstgenoemde aandeelen heeft ten doel aan de houders grooten invloed op het vervullen van de functies van directeur en commissaris toe te kennen. De bijzondere rechten bestaan uit:

Het bepalen van het aantal leden van de directic en van het college van commissarissen.

Het opmaken van een voordracht bij vacatures van dirceteuren en commissarissen, waaruit de algemeene vergadering eene benoeming moet doen.

Het vaststellen van het salaris van directeuren.

Het goedkeuren van een overdracht van aandeelen met bijzondere rechten.

De houders van deze aandeelen ontvangen geen hooger dividend dan de gewone aandeelhouders. Ten opzichte van de laatsten nemen zij bij liquidatic ook eenzelfde positie in. In verband met de bijzondere rechten, die hun zijn toegekend, kunnen echter hunne aandeclen icts hooger gewaardeerd worden dan de gewone aandeelen.

\section{A. NIERHOFF}

\section{WELKE BETEEKENIS HEEFT DE NOTEERING VAN HET INCOURANTE AANDEEL IN DE OFFICIEELE NOTEERING EN DAARBUITEN ALS GRONDSLAG VOOR DE BEPALING VAN DE WAARDE?}

Non. scolae, sed vitae discimus.

(Niet voor de school, maar voor het leven leeren wij).

Naar Seneca.

Indien men iemand vraagt in ecn koor van geschoolde ororganen de bekende ,stem uit de praktijk" te doen hooren, dan zal hij beginnen met zich zijne positie te realiseeren. En zoo gaat het derhalve ook den makelaar in effecten, den beëedigden, in het leven geschoolden makelaar, wien gevraagd wordt bovenstaand onderwerp te behandelen in een kring van tien technici. Hij doet dat gaarne, maar verwijst voor zijn standpunt bij voorbaat naar het bovenstaande motto. Hij immers, die uit hoofde van zijn vak midden in de effecten-praktijk en het effectenleven staat, realiseer't zich dagelijks, dat, wat hij aan zijn praktische kennis vergaart, rechtstreeks aan het leven ten goede komt, met alle waardeering voor de conclusies waartoe van andere zijde de theorie mag leiden.

De opgegeven titel geeft bij eerste beschouwing reeds dadelijk aanleiding tot nadere preciseering. Er rijzen de viagen:

wat is ,een incourant aandeel",

wat is "de officiëele noteering",

wat is "daarbuiten",

wat is "waarde"?
In de praktijk van den effectenhandel hier te lande kent men in de eerste plaats die fondsen, welke zijn opgenomen in de Prijscourant van de Vereeniging voor den Effectenhandel te Amstęrdam, het officiëel erkende lichaam in welks gebouw, Effectenbeurs, de officiëele beurs wordt gehouden (als zoodanig ook erkend in de Beurswet 1914). De door haar uitgegeven Prijscourant omvat de gezamenlijke officiëele noteeringen, noteeringen van - uit den aard der zaak - courante en minder courante fondsen. Voor beide groepen geven deze noteeringen op het oogenblik van hun tot stand komen als resultante van vraag en aanbod de handelswaarde van dat moment aan. Voor courante fondsen zal men die handelswaarde derhalve, bij wijze van spreken, dagelijks kummen vastleggen en al naar gelang van de mindere courantheid zal men minder noteeringen aantreffen, zal men dus op een gegeven dag oudere waardecringen zien en zal men voor het benaderen van de actueele handelswarde te rade moeten gaan bij een vakman, die deze waarde op grond van zijn kennis terzake en de door hem in te winnen imlichtingen kan benaderen en vastleggen.

"Incourante fondsen" noemt men in de praktijk al die fondsen, welke niet officiëel genoteerd zijn. (I)it zijn dus de fondsen en hunne noteeringen ,daarbuiten" zovals de titel van dit artikel vermeldt). IIum handelswaarde treft men aan in de opgaven van de huizen, welke van den handel in die fondsen hun speciaal beroep maken. De crvaring Icert dat er gecn twijfel aan bchoeft te bestaan of de publicaties van serieuze, te goeder naam en faam bekend staande huizen kunnen als juist worden aunvaard. Deze publicaties geren dus aanwijzingen over de handelswaarde van een incourant effect op dezelfde wijze als de Officiëele Prijscourant aanwijzingen geeft over de handelswaarde van een minder courant officiëel genoteerd fonds. Beide geven dus een aanwijzing van een wellicht lang vervlogen datum. Rectificatic daarop dient de vakman te geven. Dic vakman is, en dient te zijn, een beëedigd makelaar in effecten, een tegenwoordig veelal - en naar het mij voorkomt meer en meer - verguisde persoonlijkheid. Verguisd in twee opzichten: ten eerste omdat bij de waardebepaling aan de handelswaarde als regel een te geringe beteekenis wordt toegekend, in de tweede plaats omdat ook daar, waar die waardebepaling wordt gezocht, aan den practicus veclal niet wordt gedacht, respectievelijk hij opzettelijk uitgeschakeld wordt.

In dit verband zij hier vastgelegd, dat de van ouds bestaanhebbende makelaardij opnieuw is geregeld bij wet van 5 Mei 1922, in welks bepalingen de waardebepaling uitdrukkelijk is vermeld. Men leest daar: „Hij (de makelaar) legt den eed af, dat hij in het algemeen de aan hem opgelegde pligten getrouwelijk zal waarnemen en dat hij in het bijzonder de hem als makelaar opgedragen waarderingen zal doen te goeder trouw, naar zijn beste kennis en wetenschap'. Mij is geen voorbeeld bekend van een makelaar in effecten, wien het niet naleven van zijn eed ten laste zou zijn gelegd.

Alle noteeringen (courant, minder courant, incourant) al dan niet gerectificeerd door de waardeering van een makelaar in effecten, geven per saldo de verhandelingswaarde van het effect aan

In de praktijk doen zich daarbij bijzonderheden voor, welke de aandacht verdienen en welke hier dienen te worden gememoreerd.

In de eerste plaats is het duidelijk dat, ook indien zonder meer naar ,waarde" wordt gevraagd, en zeker speciaal bij incourante fondsen, bij de ,bepaling van de handelswaarde een plaats moet worden ingeruimd aan de vraag over welk aantal aandeclen het gaat. Ook in de literatuur over dit on- 